\title{
EDITORIAL
}

\section{SBFa e as perspectivas da Fonoaudiologia}

\author{
Dra. Mara Behlau
}

Uma nova Diretoria Executiva da Sociedade Brasileira de Fonoaudiologia - SBFa tomou posse no último dia 4 de janeiro, assumindo a gestão de 2010-2011. Esta gestão será coordenada por mim, Mara Behlau, à frente da presidência, Dóris Ruth Lewis na vice-presidência, Jacy Perissinoto e Letícia Lessa Mansur na diretoria científica, Vera Lúcia Garcia e Vera Lúcia Ferreira Mendes na secretaria e Juliana Algodoal e Daniela Molini-Avejonas na tesouraria. Nossa plataforma de trabalho está fundamentada em três pilares principais: identidade e exercício profissional, representatividade nacional e internacional e modernização da estrutura da sociedade.

A SBFa conta hoje com a colaboração de cinco departamentos científicos que abarcam 15 comitês. O departamento de audição e equilíbrio é coordenado por Kátia de Almeida, o de linguagem, por Clara Regina Brandão de Ávila, o de motricidade e funções orofaciais, por Zelita Caldeira Ferreira Guedes, o de saúde coletiva por Andréa Wander Bonamigo e o de voz, por Ingrid Gielow. Além desses departamentos, os conselhos administrativo e fiscal e as comissões de ensino e mérito têm funções de grande importância para viabilizar os desafios da sociedade. Um total de 70 gestores se propõe a trabalhar pela Fonoaudiologia brasileira, com entusiasmo e apreensão, pois as metas do grupo são ambiciosas.

Ter assumido a sociedade e analisar a trajetória percorrida desde 1989, ano de sua fundação, revendo os registros e documentos disponíveis, trouxe grande emoção e um sentimento profundo de reconhecimento pelo trabalho dos colegas pioneiros, que com poucos recursos e ampla visão construíram nosso órgão científico mais importante.

Para ilustrar algumas atividades já programadas para o presente ano, temos a expansão do portal da SBFa (www.sbfa.org.br), com a inclusão de 100 pequenos vídeos sobre aspectos específicos de nossa ciência e o início da série de depoimentos sobre "Conquistas Fonoaudiológicas". Diversos eventos com democrático acesso online serão desenvolvidos para contemplar a educação continuada da classe e minimizar o distanciamento geográfico. A grande celebração fonoaudiológica anual, o $18^{\circ}$ Congresso Brasileiro de Fonoaudiologia, ocorrerá na cidade de Curitiba, entre os dias 22 e 26 de setembro, no Centro de Convenções EMBRATEL, tendo como lema o "Exercício profissional: bases teóricas, avanços e realidade nacional". O formato desse evento será inovador e a expectativa é de reunir 2000 colegas participando das atividades científicas, workshops técnicos, cursos instrucionais, temas livres, pôsteres eletrônicos e premiação dos melhores trabalhos. A temática representa um movimento de confluência entre a academia e a atuação fonoaudiológica, em suas múltiplas facetas, assim como uma estratégia para facilitar a formação dos estudantes e favorecer a entrada de novos colegas no mercado de trabalho. Para o ano de 2011 já está programado o $8^{\circ}$ Congresso Internacional e $19^{\circ}$ Congresso Nacional de Fonoaudiologia, que ocorrerá na cidade de São Paulo, com o lema "Comunicação como um direito de todos". Este evento contará com a participação de colegas da American Speech-Language and Hearing Association-ASHA, a maior sociedade de fonoaudiólogos do mundo, e da International Association of Logopedics and Phoniatrics - IALP, da qual a SBFa é afiliada.

Um aspecto de imenso orgulho para todos nós é a Revista da Sociedade Brasileira de Fonoaudiologia que está em seu $15^{\circ}$ volume no presente ano, com indexação nas bases LILACS e SciELO, o que permite visibilidade à ciência nacional, uma questão de sobrevivência profissional. A revista tem recebido revisões positivas e pleiteia uma indexação ainda mais abrangente, a fim de refletir o dinamismo da produção do país e ousar participar do jogo científico em outra dimensão. A liderança de Fernanda Dreux Miranda Fernandes é um divisor de qualidade que nos permite sonhar com os olhos abertos enquanto trabalhamos para produzir pesquisas com melhores desenhos de experimento e textos mais bem estruturados.

O projeto de conduzir a Fonoaudiologia brasileira à posição que merece será o resultado de uma atuação coletiva, sustentada e de longo-prazo, com trabalho árduo e inerentes frustrações no percurso. 
Estamos atentos às demandas advindas das políticas públicas de saúde e educação, participando de grupos e ampliando representações em favor do interesse da Fonoaudiologia e de seus usuários. De todos os desafios, os dois maiores (e que estão ao nosso alcance enfrentar) são sensibilizar os próprios fonoaudiólogos sobre a importância de se associarem a SBFa e fazer com participem mais ativamente encaminhando seus melhores trabalhos para publicação em nossa revista.

A Fonoaudiologia brasileira atingiu maturidade para inspirar as novas gerações e garantir seu futuro; contudo, isso será feito com maior ou menor sacrifício dependendo do envolvimento e da generosidade dos colegas. Essa decisão é de todos e cada um responderá por ela. 